Vietnam Journal of Mechanics, NCST of Vietnam Vol. 21, 1999, No 4 (213 - 230)

\title{
RHEOLOGICAL PROPERTIES OF EMULSION OF CRUDE OIL AND WATER
}

\author{
Dúng Ngoc Hai, NGuyen Van Diep, \\ H.A NGoc Hien, NGUYen THE DUC \\ Institute of Mechanics, NCST of Vietnam \\ Phung Dinh Thuc, NguYen Thuc Khang, \\ H.A VAN BICH, TONG CANH SON \\ Joint Venture Vietsoupetro
}

\begin{abstract}
In the paper the rheological properties of crude oil of White Tiger oil-field (Vietnam) and its emulsion with sea-water, including measurement results and analytical approximation formulae for wide range of pressure, temperature and water concentration, are presented. As it is known, the crude oil of White Tiger oil-field is a high-paraffin and high-viscous oil. At the low temperature $\left(T \leq 40^{\circ} \mathrm{C}\right)$ it behaves as non-Newtonian fluid of Bingham-Shvedov group. Therefore, beside the effective viscosity, the effective dynamic shear stress is also measured and approximated. The rheological properties of crude oil and emulsion of crude oil and water are also measured and approximated for the case when the mixture contains $0.1 \%$ chemical reagent ES-3363.
\end{abstract}

\section{Introduction}

The mixture of crude oil and water used to be met in oil exploitation practice. Using the water for displacing the oil from pores, this kind of mixture can be met in production wells, in transportation pipelines, in different equipment, processing plants and etc. $[1,2]$. In order to analyse, prognose and simulate the flow behavior it is very important to have knowledge on the rheological properties of crude oil and its emulsion with water in wide range of pressure and temperature.

2. Measurement of rheological properties of crude oil and emulsion of crude oil and water

\subsection{Measurement procedure}

To investigate the rheological properties of oil and emulsion of oil and water the following main equipment is used: Rotor Visco RV-20, acquisition RC-20, software ROT. 3.0. This equipment allows to investigate the rheological properties of medium in wide range of pressure and temperature: pressure between $\sim 0$ and 
$10 \mathrm{MPa}$ and temperature between 20 and $300^{\circ} \mathrm{C}$. In order to investigate the rheological characteristics of saturated oil and its emulsion with water a special pump is necessary for keeping the invariant pressure in measurement chamber during measuring. The sensor of cylinder-in-cylinder type is used. The investigation is carried out by method of flow curves based on continuous deformation of samples. The oil used in measurement is the crude oil from White Tiger oil-field (Vietnam). The water is the sea-water. The rheological parameters are determined using the same emulsion sample with constant shear speed and temperature change in the range from 22 to $65^{\circ} \mathrm{C}$. The low limit of temperature is determined by the low limit of water temperature at the sea bottom, where the pipeline lies. The maximum of temperature equals to the preparation temperature of emulsion in the laboratory. In the experiment the maximum of shear speed is $20 \mathrm{~s}^{-1}$. This value is defined by maximum fluid velocity in the pipe. Investigating the rheological properties of crude oil and crude oil-water mixture in the area of high temperature $\left(T \geq 40^{\circ} \mathrm{C}\right)$, in which the crude oil behaves as Newtonian fluid, the temperature reduction speed is $0.35^{\circ} \mathrm{C} / \mathrm{min}$ and in the area of low temperature $\left(40 \geq T \geq 22^{\circ} \mathrm{C}\right)$, in which the crude oil behaves as non-Newtonian fluid, the temperature reduction speed is $0.15^{\circ} \mathrm{C} / \mathrm{min}$. In order to obtain the flow curve for defined shear velocity and to measure the effective dynamic shear stress at defined temperature, the shear speed is reduced gradually from maximum value to zero during 5 minutes.

The emulsion of crude oil and sea-water is prepared by the way, according to which the crude oil and water is stirred in the mixer and heated until $65^{\circ} \mathrm{C}$. The speed of the mixer is regulated in the range between 50 and 5000 circles per minute. In order to obtain the emulsion with defined drop sizes, the water is poured into oil gradually and stirred for long enough time period. In Fig. 1 the structure of emulsion of oil and water is presented for the case of $55 \%$ water concentration.

\subsection{Rheological properties of crude oil, emulsion of crude oil and water (without chemical treatment)}

In Tab. 1 measurement results of effective (viscoplastic) viscosity and dynamic shear stress are presented for oil-water mixture with water concentration from 0 to $82 \%$. Note that, the rheological properties of mixture with defined water concentration for different temperature are measured using the same sample. Beside it, in general, the measurement precision is \pm 5 .

The results (see Tab.1) show that increasing water concentration in the mixture leads to increasing the effective viscosity and dynamic shear stress and the mixture rheological properties become worse. The effective viscosity of mixture strongly increases in the region of water concentration $\varphi_{w} \geq 20 \%$. The effective viscosity and dynamic shear stress have maximum at water concentration $\varphi_{w} \sim 68 \div 70 \%$. With the temperature decreasing, the effective viscosi- 
ty of mixture significantly increases, especially in the region of low temperature $\left(40 \geq T \geq 22^{\circ} \mathrm{C}\right)$. In this region the crude oil behaves as non-Newtonian fluid. For the pure crude oil from White Tiger oil-field the non-Newtonian behavior is clearly exhibited for temperature lower than $35^{\circ} \mathrm{C}$. For the emulsion this behavior is exhibited for the some grads higher temperature.

Tab. 1. Rheological properties of crude oil, emulsion of crude oil and water at $p=1 \mathrm{~atm}$, (without chemical treatment $c=0$ )

\begin{tabular}{|c|c|c|c|c|c|c|c|c|}
\hline \multirow{2}{*}{$\begin{array}{c}\text { Temperature } \\
{ }^{\circ} \mathrm{C}\end{array}$} & \multicolumn{8}{|c|}{ Viscosity (mPa.s) vs water concentration (\%) } \\
\hline & 0 & 10 & 30 & 40 & 60 & 68 & 73 & 82 \\
\hline 80 & 4 & 5 & 6 & 6.5 & 7 & 12 & 11 & 9 \\
\hline 60 & 4.5 & 6 & 8 & 10 & 15 & 21 & 18 & 17 \\
\hline 50 & 5.0 & 7 & 11 & 22 & 52 & 57 & 55 & 53 \\
\hline 40 & 5.4 & 8 & 18 & 60 & 142 & 253 & 197 & 156 \\
\hline 35 & 11 & 20 & 54 & 180 & 450 & 671 & 617 & 283 \\
\hline 30 & 127 & 225 & 323 & 575 & 881 & 1111 & 1213 & 491 \\
\hline 26 & 481 & 725 & 1120 & 1482 & 1635 & 1782 & 1563 & 616 \\
\hline Temperature & \multicolumn{8}{|c|}{ Dynamic shear stress $(\mathrm{Pa})$ vs water concentration $(\%)$} \\
\hline 50 & 0 & 0 & 0 & 0 & 0 & 0 & 0 & 0 \\
\hline 40 & 0 & 0.2 & 0.4 & 0.7 & 1.8 & 2.6 & 2.3 & 1.2 \\
\hline 35 & 0 & 2.3 & 3.4 & 3.5 & 4.2 & 5.7 & 4.5 & 1.5 \\
\hline 30 & 4.2 & 9.8 & 5.8 & 6.6 & 9. & 9.2 & 7.5 & 6.2 \\
\hline 26 & 16.6 & 18.1 & 25. & 26.7 & 33.1 & 35.6 & 14.2 & 8.4 \\
\hline
\end{tabular}

\subsection{Rheological properties of crude oil, emulsion of crude oil and water with chemical treatment}

To reduce the pour-point temperature and improve the dynamical characteristics of crude oil and emulsion of crude oil and water, in practice the chemical reagent is used. In this section the measurement results of rheological properties of crude oil, and emulsion of crude oil and water with chemical treatment using reagent ES-3363 of concentration $c=0.1 \%$ are presented.

Firstly the sample (crude oil or emulsion of crude oil and water) is heated until $65^{\circ} \mathrm{C}$. This temperature is kept for $\sim 20$ minutes in order to melt all existed in crude oil paraffin crystall amount. After that the chemical reagent is mixed into sample with defined concentration of 1000 grams per ton. The rheological properties (effective viscosity and dynamic shear stress) of obtained mixture are 
measured by viscosimeter according to before defined program using $\mathrm{PC}$ and appropriate software (see Tab.2).

Tab. 2. Rheological properties of crude oil, emulsion of crude oil and water at $p=1 \mathrm{~atm}$, with chemical treatment using reagent ES-3363 of $c=0.1 \%$

\begin{tabular}{|c|c|c|c|c|c|c|c|c|}
\hline \multirow{2}{*}{$\begin{array}{c}\text { Temperature } \\
{ }^{\circ} \mathrm{C}\end{array}$} & \multicolumn{8}{|c|}{ Viscosity (mPa.s) vs water concentration (\%) } \\
\hline & 0 & 10 & 30 & 40 & 60 & 68 & 73 & 82 \\
\hline 80 & 4.5 & 5 & 11 & 13 & 18 & 21 & 19 & 15 \\
\hline 60 & 5.2 & 6 & 12 & 15 & 24 & 25 & 21 & 16 \\
\hline 50 & 6.0 & 8 & 15 & 17 & 28 & 34 & 24 & 21 \\
\hline 40 & 7 & 9 & 19 & 27 & 35 & 38 & 34 & 29 \\
\hline 35 & 8 & 12 & 35 & 52 & 62 & 71 & 67 & 51 \\
\hline 30 & 15 & 23 & 63 & 137 & 185 & 327 & 197 & 107 \\
\hline 28 & 28 & 49 & 152 & 309 & 415 & 466 & 401 & 393 \\
\hline 26 & 42 & 87 & 365 & 401 & 723 & 892 & 794 & 625 \\
\hline 24 & 89 & 134 & 491 & 667 & 969 & 981 & 924 & 726 \\
\hline Temperature & \multicolumn{8}{|c|}{ Dynamic shear stress $(\mathrm{Pa})$ vs water concentration $(\%)$} \\
\hline 40 & 0 & 0 & 0 & 0 & 0 & 0 & 0 & 0 \\
\hline 35 & 0 & 0 & 0 & 0.3 & 0 & 0 & 0.3 & 0 \\
\hline 30 & 0 & 0.5 & 1.3 & 7.9 & 4.9 & 10.2 & 7.3 & 5.2 \\
\hline 28 & 0 & 1.3 & $7: 9$ & 8.6 & 10.9 & 15.1 & 12.8 & 8.4 \\
\hline 26 & 0.8 & 3.5 & 12.8 & 13.9 & 15.2 & 20. & 15.3 & 11.7 \\
\hline 24 & 3.5 & 6.2 & 19.1 & 20.1 & 21.8 & 23.6 & 24.1 & 18.5 \\
\hline
\end{tabular}

The comparison of Tab. 2 with Tab. 1 shows the influence of chemical treatment on the behavior of emulsion and its rheological properties. It is clear that, the chemical treatment significantly improves dynamical characteristics of oil and its mixture with water, especially in the region of low temperature. In this region in comparison with the case without chemical treatment the effective viscosity and dynamic shear stress are quantitatively much smaller. Generally they are reduced in $\sim 2$ times and even more. Beside it, in this case the non-Newtonian behavior of emulsion appears only at temperature $\sim 35^{\circ} \mathrm{C}$ and lower.

\subsection{Rheological properties of emulsion of crude oil and water saturated with gas at high pressure conditions}

To model the motion of oil along the working production well the dynamic characteristics of crude oil and emulsion of crude oil and water at high pressure 
and high temperature conditions are necessary. In these conditions it should take into account also saturation of oil with gas (light fractions of hydrocarbons).

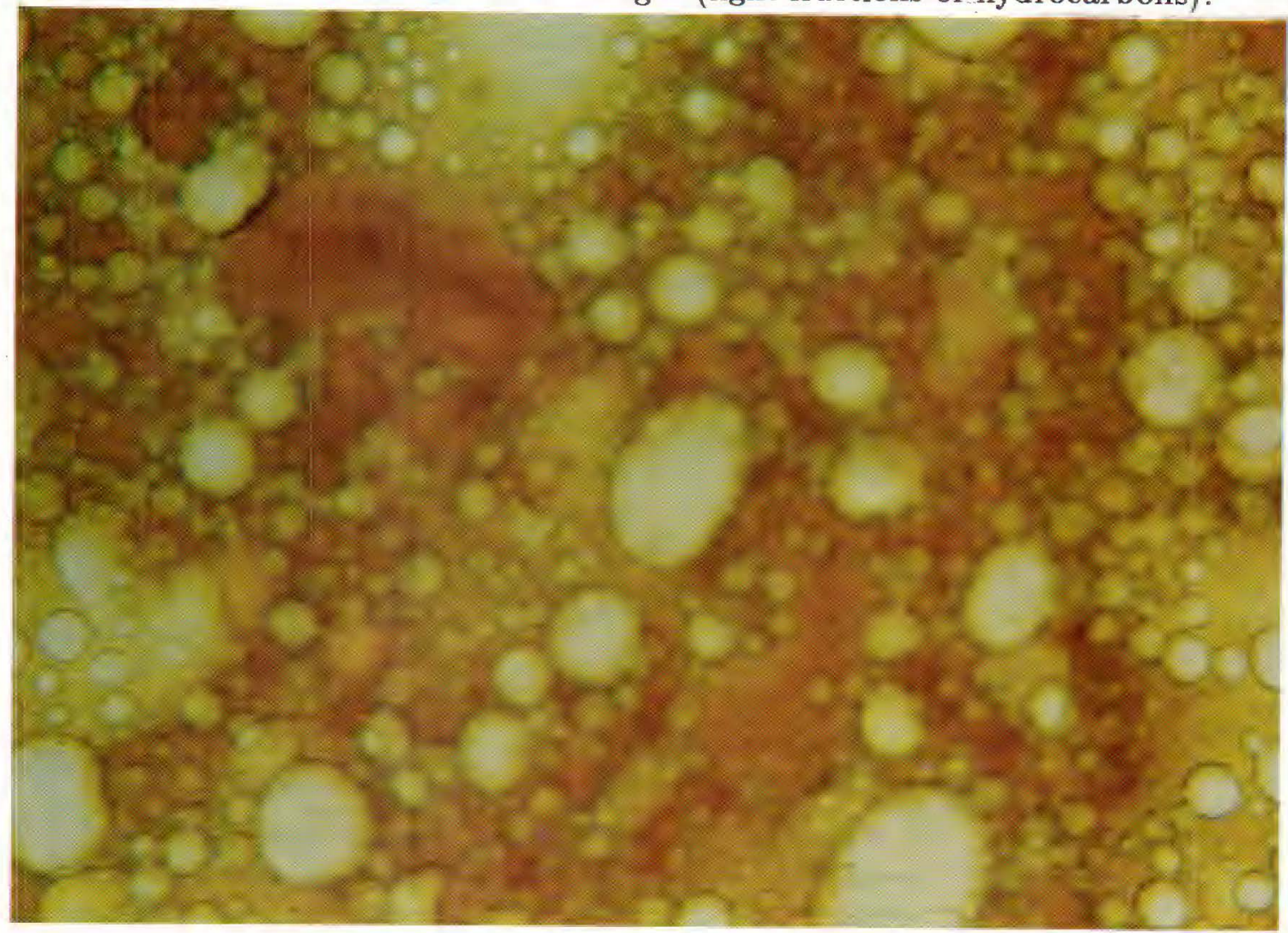

Fig. 1. Structure of elmulsion of crude oil of White Tiger oil-field and seawater for the case $\varphi_{w}=0.55 \%$. (Picture is increased in 40 times)

To investigate the rheological properties of emulsion in this case the viscosimeter RV-20 with cylinder sensor D-300 is used. The sample is prepared by mixture of heated oil with sea-water. After that the emulsion is poured into closed PVT box for saturation with gas at different pressures. The saturation of emulsion with gas is implemented at temperature $T \leq 50^{\circ} \mathrm{C}$ and pressures 2 and $4 \mathrm{MPa}$. After saturating, the sample of emulsion is kept in the high pressure box $500-15 \mathrm{P}$ with volume $500 \mathrm{ml}$. In this box the sample can be kept until pressure 5000 Psi $(\sim 34.4$ $\mathrm{MPa}$ ) and temperature $180^{\circ} \mathrm{C}$.

Before measuring the sensor $\mathrm{D}-300$ is heated until $50^{\circ} \mathrm{C}$, i.e. equals the sample temperature. After that the sample is pumped by pump Mercury from high pressure box 500-15P into sensor D-300. The volume of sensor is $70 \mathrm{ml}$. During the transportation of sample into sensor D-300 the internal pressure of high pressure box $500-15 \mathrm{P}$ is kept above saturation pressure of emulsion. The measurement procedure in this case is similar to the measurement procedure in the above case of atmospheric condition. In Tab. 3 the results of measurement of rheological properties of emulsion of crude oil and water with different water concentration, 
for two pressure conditions 2 and $4 \mathrm{MPa}$, and for wide range of temperature are presented.

Tab. 3. Rheological properties of emulsion saturated with gas, (without chemical treatment $\mathrm{c}=0$ )

\begin{tabular}{|c|c|c|c|c|}
\hline \multirow{3}{*}{$\begin{array}{c}\text { Temperature } \\
\left({ }^{\circ} \mathrm{C}\right)\end{array}$} & \multicolumn{4}{|c|}{ Viscosity (mPa.s) vs water concentration (\%) } \\
\hline & \multicolumn{3}{|c|}{ Saturation pressure, $2 \mathrm{MPa}$} & \multirow{2}{*}{$\frac{\text { Saturation pressure, } 4 \mathrm{MPa}}{21 \%}$} \\
\hline & $11 \%$ & $21 \%$ & $28 \%$ & \\
\hline 50 & 8 & 9 & 12 & 10 \\
\hline 45 & 10 & 11 & 16 & 15 \\
\hline 40 & 12 & 14 & 20 & 20 \\
\hline 35 & 19 & 19 & 33 & 27 \\
\hline 30 & 64 & 76 & 93 & 48 \\
\hline 28 & 87 & 86 & 123 & 54 \\
\hline 26 & 103 & 119 & 192 & 76 \\
\hline 24 & 123 & 148 & 226 & 106 \\
\hline 22 & 137 & 189 & 250 & 163 \\
\hline Temperature & \multicolumn{4}{|c|}{ Dynamic shear stress $(\mathrm{Pa})$ vs water concentration $(\%)$} \\
\hline 40 & 0.5 & 0.8 & 0.7 & 0.7 \\
\hline 35 & 1.25 & 2.0 & 3.0 & 2.1 \\
\hline 30 & 4.8 & 6.0 & 4.9 & 4.6 \\
\hline 28 & 5.0 & 6.3 & 5.2 & 5.2 \\
\hline 26 & 5.1 & 6.8 & 7.1 & 5.6 \\
\hline 24 & 5.3 & 7.5 & 7.8 & 6.0 \\
\hline 22 & 6.6 & 9.0 & 8.8 & 7.04 \\
\hline
\end{tabular}

Comparing Tab. 3 with Tạb. 2 we can see that the gas saturation leads to significant reduction of emulsion effective viscosity and dynamic shear stress. In this case the non-Newtonian behavior is exhibited at temperature $\sim 40^{\circ} \mathrm{C}$ and a little bite higher.

3. Approximation of rheological properties of crude oil, emulsion of crude oil and water

\subsection{Approximation for oil viscosity $\left(\varphi_{w}=0\right)$}

For crude oil there is a number of formulae recomended in published literature. For example, in [3] the following correlation is proposed: 
For $p \leq p_{b}$ ( $p_{b}$ is a buble-point pressure):

$$
\mu_{0}=A \mu_{0 D}^{B},
$$

where $\mu_{0}$ is a oil viscosity (cp); $\mu_{O D}=10^{x}-1.0$ is a dead or gas-free oil viscosity; $x=Y T^{c} ; Y=10^{a+b A P I} ; T$ is temperature $\left({ }^{\circ} \mathrm{F}\right) ; A P I=141.5 / \gamma_{0}-131.5$; $\gamma_{0}=\rho_{0} / \rho_{w}$ is a ratio of oil density and water density at standard conditions; $A=a_{1}\left(R_{S}-R_{S A}\right)^{a_{2}} ; B=b_{1}\left(R_{S}+R_{S A}\right)^{b_{2}} ; R_{S}$ is solution gas; $R_{S A}=150$ (scf/STB); $a_{1}=10.715 ; a_{2}=-0.515 ; b_{1}=5.44 ; b_{2}=-0.338$.

In [4] the coefficients are recomended:

$a=3.0324 ; b=0.0203 ; c=-1.163$.

For the crude oil of White Tiger oil-field the following values are recomended:

$a-b A P I=0.4108 ; c=-0.25$. (without chemical treatment)

and:

$a-b A P I=0.7408 ; c=-0.39$ (with chemical treatment of $c=0.1 \%$ ).

It should be noted that, the formula (3.1) is proposed for normal (Newtonian) fluid (crude oil). For non-Newtonian fluid (crude oil) the viscosity is interpolated using measurement data and splain function method.

For $p>p_{b}$ :

$$
\mu_{0}=\mu_{0 b}\left(p / p_{b}\right)^{m},
$$

where $\mu_{0 b}$ is a viscosity of fluid at $p_{b}, m$ is a coefficient depended on $p$.

\subsection{Effective viscosity of emulsion of oil and water}

There is a number of formulae for determination of the effective viscosity $\mu_{e}$ of oil-in-water $(o / w)$ or water-in-oil $(w / o)$ emulsion [5-17].

1. Polynomial correlations. Linear formula:

$$
\mu_{e}=\mu_{c}\left(1+k \varphi_{d}\right),
$$

where subscripts $c$ and $d$ denote the characteristics of continuous and dispersed phases of emulsion, respectively. Einstein recomends $k=2.5$ and this correlation is good for $\varphi_{d} \leq 5 \%$.

The Taylor correlation using (3.3) with

$$
k=2.5 \frac{\mu_{d}+0.4 \mu_{c}}{\mu_{c}+\mu_{d}}
$$

is recomended for $\varphi_{\dot{a}} \leq 16-17 \%$.

Hopal correlation using (3.3) with

$$
k=2.5 \frac{\mu_{d}+0.4 \mu_{c}+\frac{2 \mu_{c} \mu_{d}}{K r}}{\mu_{d}+\mu_{c}}
$$


is recomended for $\varphi_{d} \leq 5 \%$. In the formula (3.5) $K$ is a constant, $r$ is a mean diameter of drops. The correlation (3.3) with (3.5) is only correlation taken into account the influence of drop sizes.

Monson proposes the polynomial correlation based on data of California oil:

$$
\mu_{e}=\mu_{0}\left(1+2.5 \varphi_{w}+2.19 \varphi_{w}^{2}+27.45 \varphi_{w}^{3}\right)
$$

where subscripts $o$ and $w$ refer to the characteristics of oil and water phases, respectively. The formula (3.6) is recomended for $\varphi_{w} \leq 50 \%$.

Levin and Layton correlation:

$$
\mu_{e}=\mu_{0}\left[1+2.5\left(\varphi_{w}+\varphi_{w}^{5 / 3}+\varphi_{w}^{11 / 3}\right)\right]
$$

is recomended for $\varphi_{w} \leq 0.4$.

2. Exponential correlation:

$$
\mu_{e}=\mu_{c} \exp \left(\frac{k_{1} \varphi_{d}}{1-k_{2} \varphi_{d}}\right) .
$$

There is a number of authors using the formula (3.8) for analysing measurement data. Gillies and Shook recomend $k_{1}=175, k_{2}=1$ for heavy $o / w$ emulsion. Rose and Marsden recomend $k_{1}=4.08, k_{2}=0$ for crude oil-in-seawater emulsion, Camy et al. recomend $6<k_{1}<7, k_{2}=0$ for $o / w$ emulsion and $-4<k_{1}<-3$, $k_{2}=0$ for $w / o$ emulsion, Mao and Marsden recomend $k_{1}=3.53, k_{2}=0$ for $w / o$ emulsion. $\mathrm{Pal}$ and Rhodes, and Mewes et al. recomend $k_{1}=2.5, k_{2}=0$. In the last case $\left(k_{1}=2.5, k_{2}=0\right)$ for $\varphi_{d} \ll 1$ the expression (3.8) returns to Einstein formula.

3. Brinkman formula:

$$
\mu_{e}=\mu_{c}\left(1-\varphi_{d}\right)^{-2.5} .
$$

Note that, if $\varphi_{d} \ll 1$ the formula (3.8) approachs to the Einstein correlation.

4. Vermeulen formula:

$$
\mu_{e}=\left(1+\frac{1.5 \mu_{d}}{\mu_{d}+\mu_{c}}\right) \frac{\mu_{c}}{1-\varphi_{d}}
$$

5. In [8] the effective viscosity of emulsion is proposed in the following form:

$$
\mu_{e}=\mu_{c} \mu_{r} p^{n} f(r),
$$

where $\mu_{r}$ is the relative viscosity; $r$ is the droplet diameter of dispersed phase. 
Pal et al. propose the following expression for the relative viscosity:

$$
\mu_{r}=\left[1+\frac{k_{1} \varphi_{d}}{1.187-k_{1} \varphi_{d}}\right]^{2.5}
$$

The influence of temperature is took into account through $\mu_{c}$ :

$$
\mu_{c}=k_{2} \exp \left(k_{3} T\right) \text {. }
$$

Generalizing (3.11) and (3.12) in [9] the following formula for $\mu_{e}$ is proposed:

$$
\mu_{e}=\mu_{c}\left[1+\frac{k_{1} \varphi_{d}}{1.187-k_{1} \varphi_{d}}\right]^{2.5} p^{n}
$$

where $k_{1}=1.4556, k_{2}=0.4526$ (for $w / o$ emulsion) and 0.002 (for $o / w$ emulsion); $k_{3}=-0.0458 ; n=-0.06$.

Note that, for all correlations (3.3)-(3.10) the influence of pressure and temperature change on $\mu_{e}$ is not analysed in details and proposed it is taken into account through $\mu_{c}$. Beside the influence through $\mu_{c},(3.11)$ and (3.14) propose to take into account the influence of pressure separately through the factor $p^{n}$. The influence of dispersed drop size is proposed to take into account in (3.5) and (3.11).

To approach the rheological properties of crude oil of White Tiger oil-field and its emulsion with sea-water the expanded polynomial formulae are used. For this purpose the emulsion is divided into two regions. The region of $w / o$ emulsion and the region of $o / v$ emulsion. The inversion point in this case is the point with water cut $\varphi_{w} \sim 68 \%$.

a. The case without chemical treatment $(c=0)$ :

- Effective viscosity of $w / o$ emulsion:

$$
\mu_{e}=\mu_{c}\left\{1+2.5 \varphi_{w}+a_{1}(T) \exp \left[-a_{3}(p-1)\right] \varphi_{w}^{2}+a_{2}(T) \exp \left[a_{3}(p-1)\right] \varphi_{w}^{3}\right\} \text {. }
$$

At $p=1 \mathrm{~atm},(3.15)$ has the following form:

$$
\mu_{e}=\mu_{0}\left[1+2,5 \varphi_{w}+a_{1}(T) \varphi_{w}^{2}+a_{2}(T) \varphi_{w}^{3}\right]
$$

i.e. the form of (3.6); but the coefficients $a_{1}, a_{2}$ are functions of temperature.

For the emulsion of crude oil of White Tiger oil-field with sea-water the coefficients have the following values:

$$
\begin{array}{lll}
a_{1}=11.28 ; & a_{2}=-13.74 & \text { for } 25<T \leq 27^{\circ} \mathrm{C} \\
a_{1}=18.66 ; & a_{2}=-8.91 & \text { for } 27<T \leq 32.5^{\circ} \mathrm{C} \\
a_{1}=24.82 ; & a_{2}=145.31 & \text { for } 32.5<T<37.5^{\circ} \mathrm{C} \\
a_{1}=-18.9 ; & a_{2}=160.68 & \text { for } 37.5<T<45^{\circ} \mathrm{C} \\
a_{1}=-1.68 ; & a_{2}=33.1 & \text { for } 45<T<55^{\circ} \mathrm{C} \\
a_{1}=-3.78 ; & a_{2}=11.36 & \text { for } 55<T \leq 70^{\circ} \mathrm{C} \\
a_{1}=-8.14 ; & a_{2}=12.12 & \text { for } T>70^{\circ} \mathrm{C}
\end{array}
$$


For all cases $a_{3}=0.1$.

- Effective viscosity of $o / w$ emulsion $\left(\varphi_{w}>68 \%\right)$ :

- For water concentration $\varphi_{w}: 85<\varphi_{w} \leq 100 \%$ the Taylor correlation (3.4) is used.

- For water concentration $\varphi_{w}$ : $68<\varphi_{w}<85 \%$ the interpolation using 3 points $\varphi_{w}=68 ; 73$ and $82 \%$ is used.

For $T \leq 40^{\circ} \mathrm{C}: \mu_{73}=0.86 \mu_{68}, \mu_{82}=0.45 \mu_{68}$.

For $T>40^{\circ} \mathrm{C}: \mu_{73}=0.91 \mu_{68}, \mu_{82}=0.83 \mu_{68}$.

b. The case with chemical treatment using ES-\$969 of concentration 0.1\%:

- For $w / o$ emulsion $\left(\varphi_{w}<68 \%\right)$ :

In this case the coefficients (3.15) have the following values:

$$
\begin{array}{lll}
a_{1}=72.42 ; & a_{2}=-49.23 & \text { for } 25<T<27^{\circ} \mathrm{C} \\
a_{1}=75.37 ; & a_{2}=-66.85 & \text { for } 27<T<29^{\circ} \mathrm{C} \\
a_{1}=22.53 ; & a_{2}=22.21 & \text { for } 29<T<32.5^{\circ} \mathrm{C} \\
a_{1}=43.39 ; & a_{2}=-45.21 & \text { for } 32.5<T<37.5^{\circ} \mathrm{C} \\
a_{1}=17.26 ; & a_{2}=-16.81 & \text { for } 37.5<T<45^{\circ} \mathrm{C} \\
a_{1}=5.57 ; & a_{2}=1.07 & \text { for } 45<T<55^{\circ} \mathrm{C} \\
a_{1}=8.01 ; & a_{2}=-4.63 & \text { for } 55<T \leq 70^{\circ} \mathrm{C} \\
a_{1}=7.69 ; & a_{2}=-5.29 & \text { for } T>70^{\circ} \mathrm{C}
\end{array}
$$

* For $o / w$ emulsion:

The procedure is similar to the case a).

In Figs. 2-8 the results of calculation using (3.15) and (3.17) or (3.18) are presented. In Figs. 2-4 the approximation is compared with measurement data (see 2). In Figs. 5-8 the 3-D graphics are presented. From the figures it can be seen that the average difference between measurement data and analytical approximation has the order of $4-12 \%$.

\subsection{Effective dynamic shear stress of emulsion of oil and water}

a. The case without chemical treatment $(c=0)$ :

At $p=1 \mathrm{~atm}$, in order to approximate the effective dynamic shear stress of emulsion the full quadratic form with respect to temperature $T$ and water concentration $\varphi_{w}$ is used:

$$
\tau_{0}\left(p=1 a t m, T, \varphi_{w}\right)=\tau_{01}=\exp \left(a_{1}+a_{2} T+a_{3} \varphi_{w}+a_{4} T^{2}+a_{5} T \varphi_{w}+a_{6} \varphi_{w}^{2}\right)
$$

where:

$$
\begin{array}{lll}
a_{1}=16.9783 ; & a_{2}=-0.7406 ; & a_{3}=4.4597 \times 10^{-3} ; \\
a_{4}=7.4194 \times 10^{-3} ; & a_{5}=2.9624 \times 10^{-4} ; & a_{6}=4.1284 \times 10^{-5}
\end{array}
$$




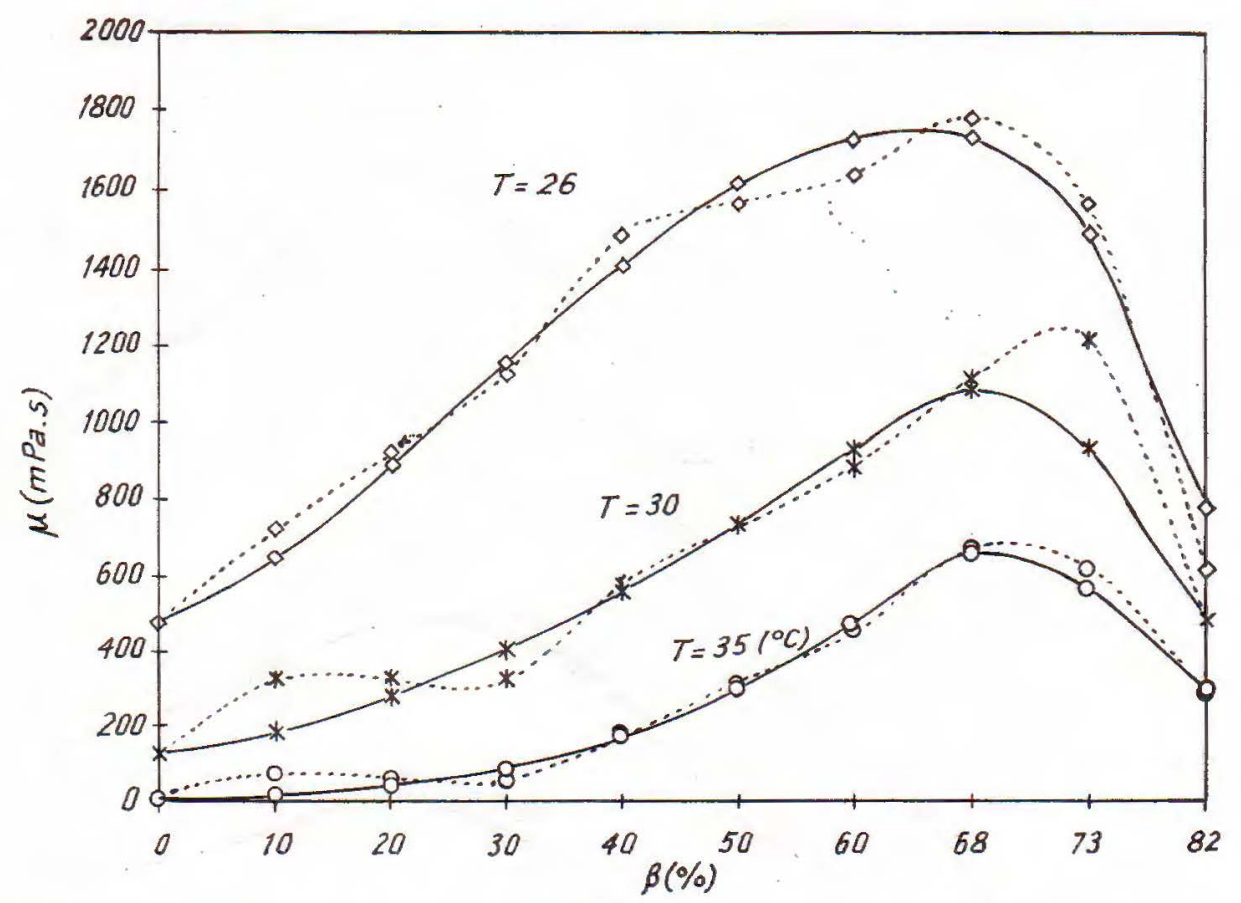

Fig. 2. Comparison of calculation results of (3.15), (3.17) (continuous lines) with measurement data (dash lines) of different water concentration, temperature,

for $p=1 \mathrm{~atm}$ and for the case without chemical treatment $(c=0)$

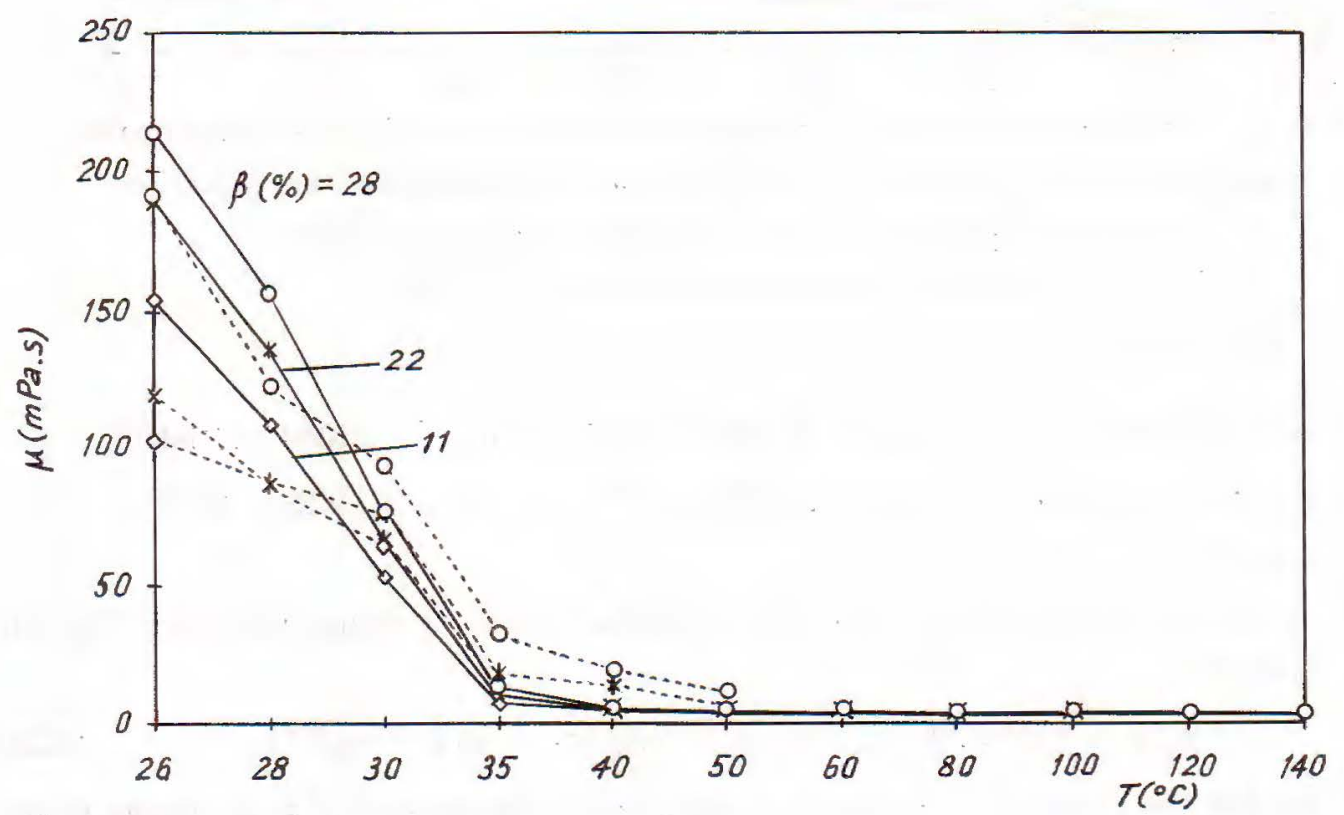

Fig. 9. Comparison of calculation results of (3.15), (3.17) (continuous lines) with measurement data (dash lines) of different water concentration, temperature,

for $p=20 \mathrm{~atm}$ and for the case without chemical treatment $(c=0)$ 


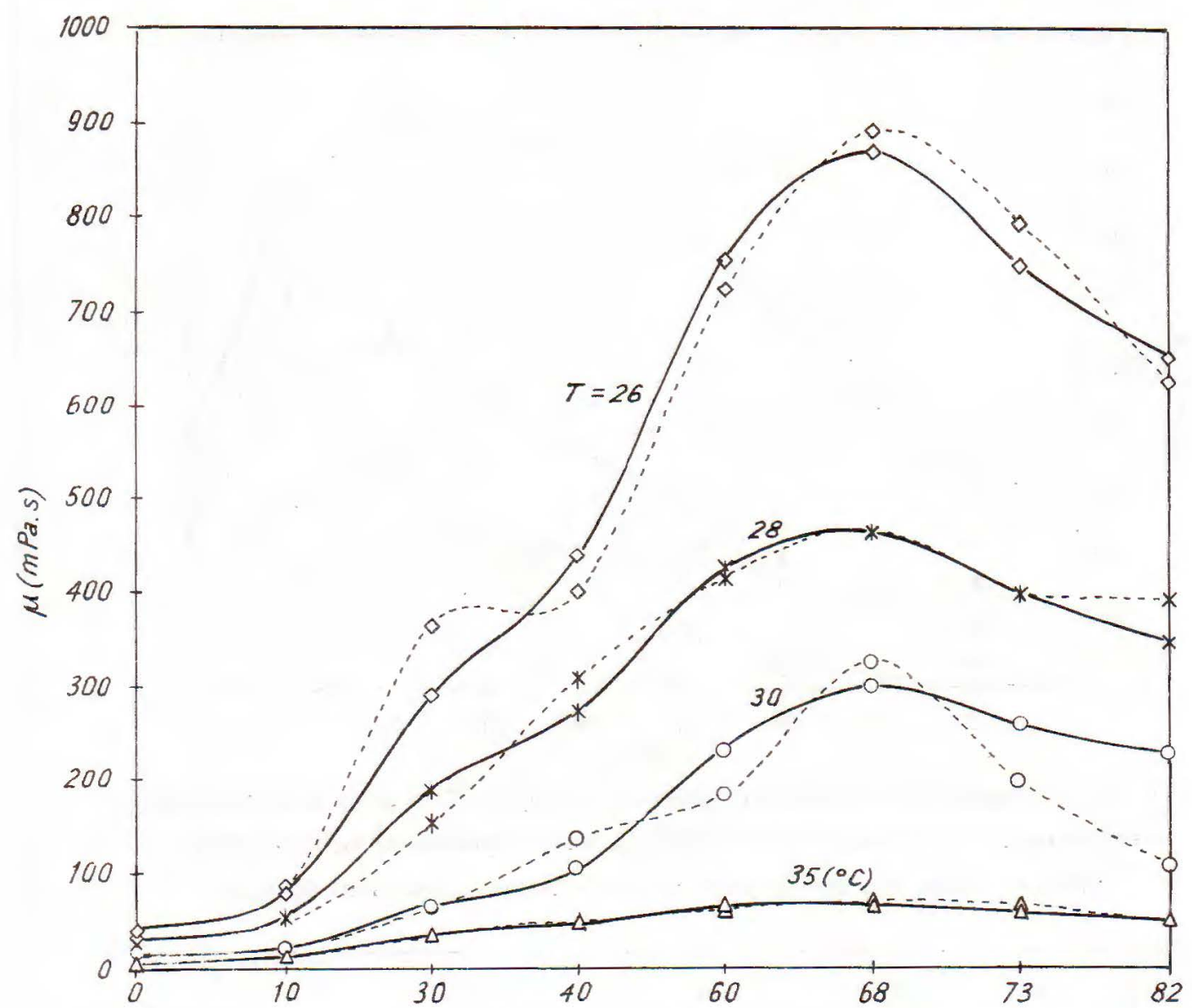

Fig. 4. Comparison of calculation results of (3.15), (3.18) (continuous lines) with measurement data (dash lines) of different water concentration, temperature, for $p=20 \mathrm{~atm}$ and for the case with chemical treatment using ES-3363 of concentration $c=0.1 \%$

for $\varphi_{w} \leq 68 \%$, and:

$$
\begin{array}{lll}
a_{1}=22.0150 ; & a_{2}=-8.4087 \times 10^{-2} ; & a_{3}=-3.6617 \times 10^{-1} ; \\
a_{4}=1.9422 \times 10^{-4} ; & a_{5}=8.0779 \times 10^{-4} ; & a_{6}=2.1226 \times 10^{-3}
\end{array}
$$

for $\varphi_{w}>68 \%$.

For pure crude oil $\left(\varphi_{w}=0\right)$ the formula (3.19) is simplified and has the following form:

$$
\tau_{0}\left(p=1 \text { atm, } T, \varphi_{w}\right)=\tau_{11}=\exp \left(a_{1}+a_{2} T+a_{4} T^{2}\right) .
$$

In $[18\}$ for the case $\varphi_{w}=0$ the time dependent behaviour of $\tau_{0}$ is investigated.

For $p>1 \mathrm{~atm}$, in order to approximate the effective dynamic shear stress of emulsion the followirg expression is used:

$$
\tau_{0}=\tau_{01} \exp \left\{(p-1)\left[a_{7}+a_{8} T+a_{9}(p-1)+a_{10} T^{2}+a_{11} T(p-1)+a_{12}(p-1)^{2}\right]\right\},
$$




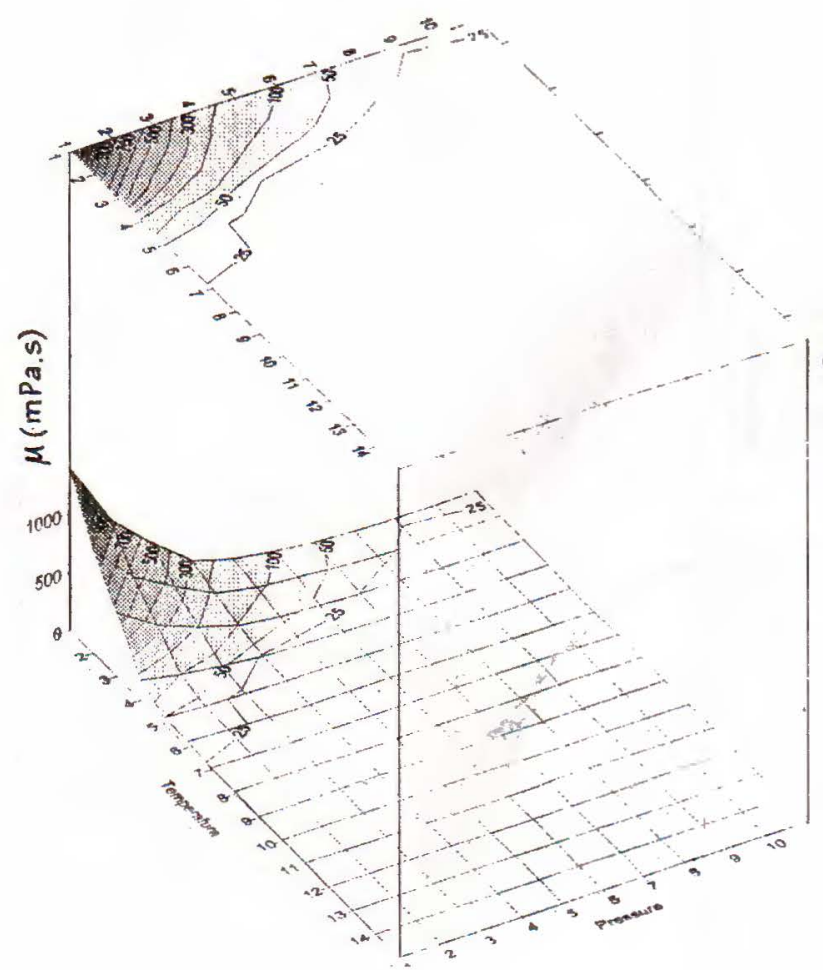

Fig. 5. Effective viscosity of emulsion of oil and water vs pressure and temperature (water concentration $\varphi_{w}=40 \%$ )

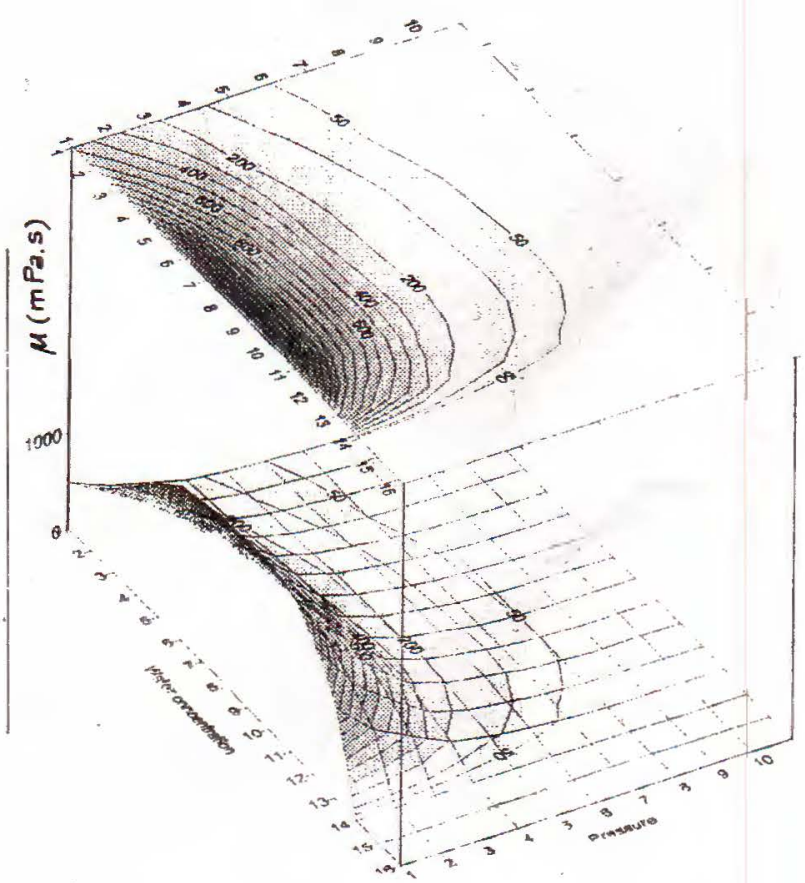

Fig. 6. Effective viscosity of oil and water vs pressure and water concentration at $T=26^{\circ} \mathrm{C}$

Scale for Pressure

Number: $\quad \begin{array}{llllllllll}1 & 2 & 3 & 4 & 5 & 6 & 7 & 8 & 9 & 10\end{array}$

accords to: 15102030406080100120 (atm)

Scale for Temperature

Number: $\begin{array}{lllllllllllllll}1 & 2 & 3 & 4 & 5 & 6 & 7 & 8 & 9 & 10 & 11 & 12 & 13 & 14\end{array}$

accords to: $262830354045505560657080100120\left({ }^{\circ} \mathrm{C}\right)$

Scale for Water concentration

Number: $\begin{array}{llllllllllllllll}1 & 2 & 3 & 4 & 5 & 6 & 7 & 8 & 9 & 10 & 11 & 12 & 13 & 14 & 15 & 16\end{array}$

accords to: 01020304050556065687075808590100 (\%)

where:

$$
\begin{aligned}
& a_{7}=-1.1792 \times 10^{-6} ; \quad a_{8}=4.4108 \times 10^{-2} ; \quad a_{9}=-6.2248 \times 10^{-2} ; \\
& a_{10}=-5.4265 \times 10^{-4} ; \quad a_{11}=-1.6866 \times 10^{-4} ; \quad a_{12}=1.1764 \times 10^{-3} \text {. }
\end{aligned}
$$

b. The case with chemical treatment using ES-\$363 of concentration 0.1\%: 


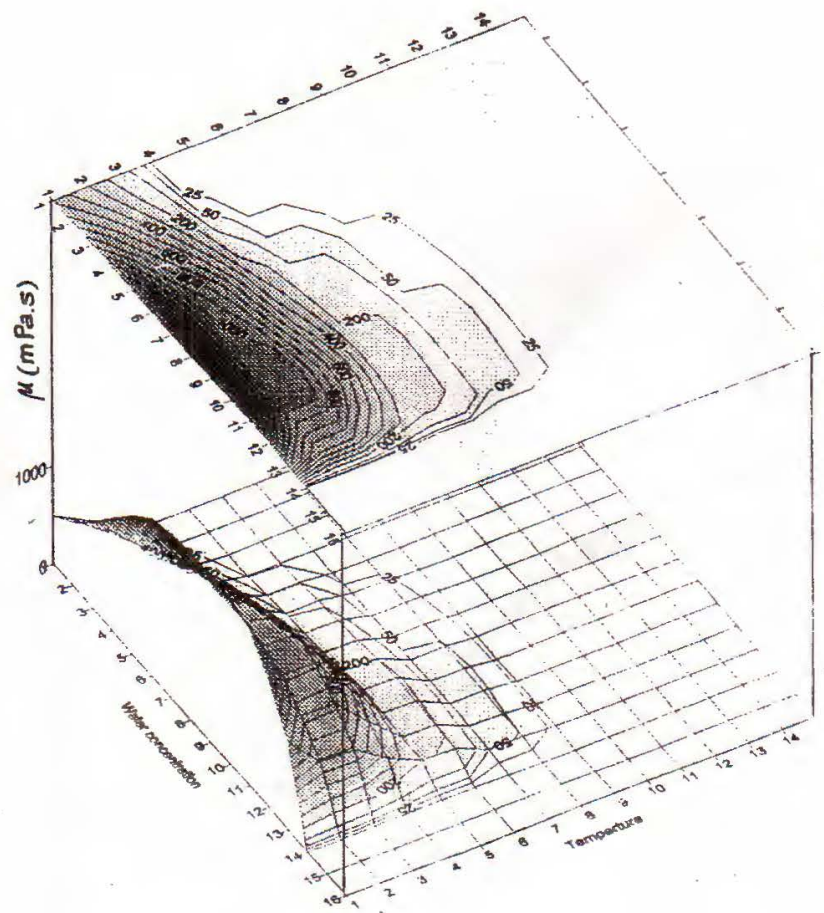

Fig. 7. Effective viscosity of emulsion of oil and water vs temperature and water concentration at $p=1 \mathrm{~atm}$

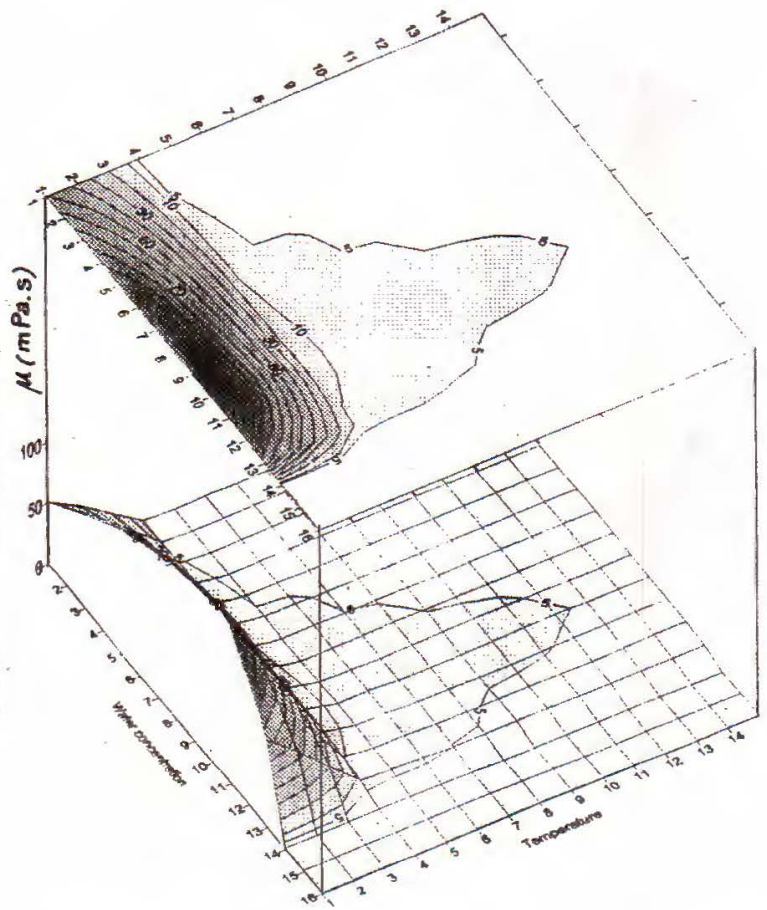

Fig. 8. Effective viscosity of emulsion of oil and water vs temperature and water concentration at $p=40 \mathrm{~atm}$

Scale for Temperature

Number: $\begin{array}{llllllllllllll}1 & 2 & 3 & 4 & 5 & 6 & 7 & 8 & 9 & 10 & 11 & 12 & 13 & 14\end{array}$

accords to: $262830354045505560657080100120\left({ }^{\circ} \mathrm{C}\right)$

Scale for Water concentration

Number: $\begin{array}{lllllllllllllllll}1 & 2 & 3 & 4 & 5 & 6 & 7 & 8 & 9 & 10 & 11 & 12 & 13 & 14 & 15 & 16\end{array}$

accords to: 01020304050556065687075808590100 (\%)

In this case, at $p=1 \mathrm{~atm}$, the formula (3.19) is used with the following coefficient values:

$$
\begin{array}{lll}
a_{1}=-14.4612 ; & a_{2}=1.4237 ; & a_{3}=7.7352 \times 10^{-2} ; \\
a_{4}=-3.3157 \times 10^{-2} ; & a_{5}=9.3831 \times 10^{-4} ; & a_{6}=-8.7688 \times 10^{-4}
\end{array}
$$

for $\varphi_{w} \leq 68 \%$, and:

$$
\begin{array}{lll}
a_{1}=-29.647 ; & a_{2}=2.7941 ; & a_{3}=-3.4430 \times 10^{-2} \\
a_{4}=-5.4198 \times 10^{-2} ; & a_{5}=-8.8987 \times 10^{-4} ; & a_{6}=1.5931 \times 10^{-4}
\end{array}
$$


for $\varphi_{w}>68 \%$.

For $p>1 \mathrm{~atm}$, the formula (3.21) is used with the following coefficient values:

$$
\begin{aligned}
a_{7} & =-1.1792 \times 10^{-6} ; \quad a_{8}=4.4108 \times 10^{-2} ; \\
a_{10} & =-5.4265 \times 10^{-4} ; \quad a_{11}=-1.6866 \times 10^{-4} ; \quad a_{12}=1.1764 \times 10^{-3} .
\end{aligned}
$$

In Fig. 9-11 the comparison of calculation results with measurement data is presented for different temperature, water concentration (Fig. 9, 10) and for the case with chemical treatment (Fig.11). From the figures it can be seen that the analytical approximation fits good mearusement data and difference between them mainly has the order smaller than 5 , i.e. smaller the order of measurement precision.

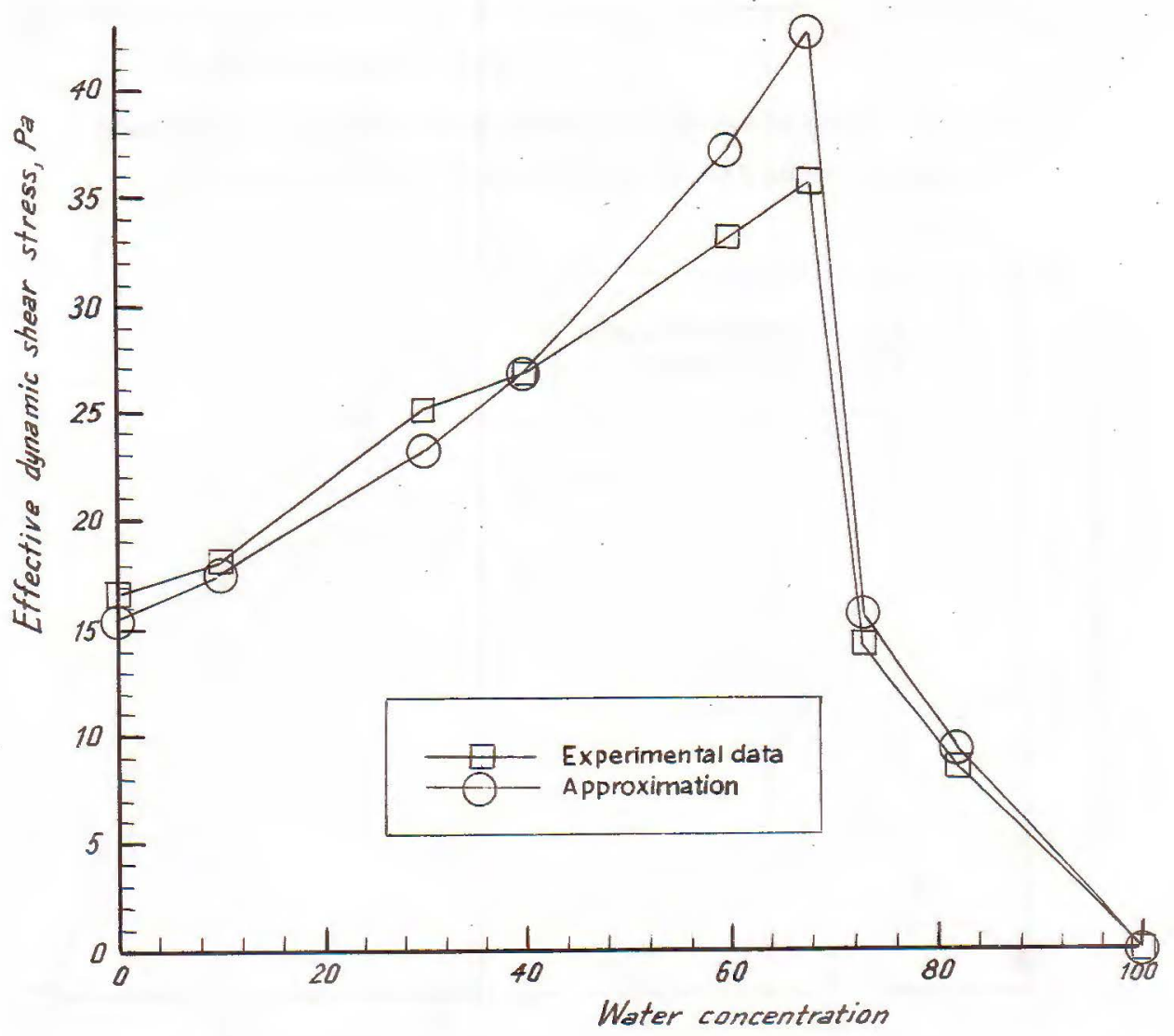

Fig. 9. Comparison of calculation results of $(3.19),(3.20)$ with measurement data for $p=1 \mathrm{~atm}, T=26^{\circ} \mathrm{C},(c=0)$ 


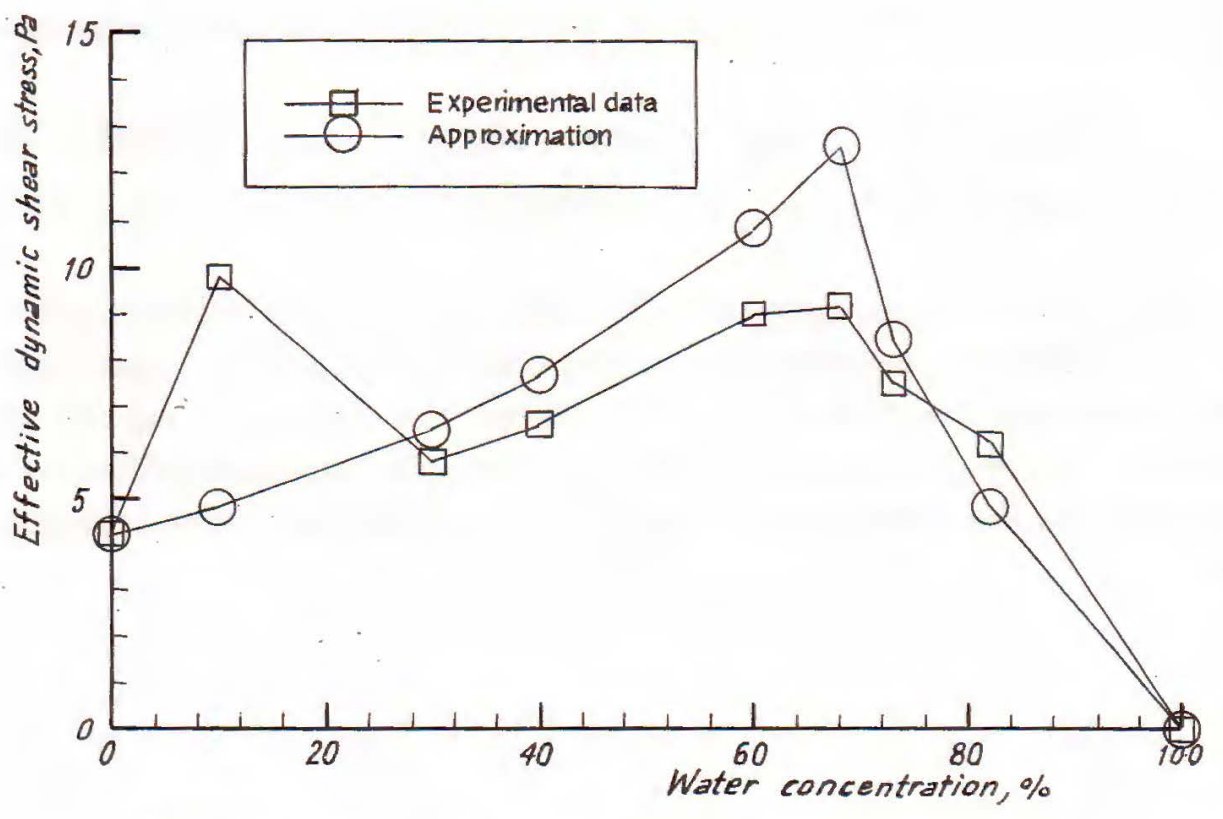

Fig. 10. Comparison of calculation results of (3.19), (3.20) with measurement data for $p=1 \mathrm{~atm}, T=30^{\circ} \mathrm{C},(c=0)$

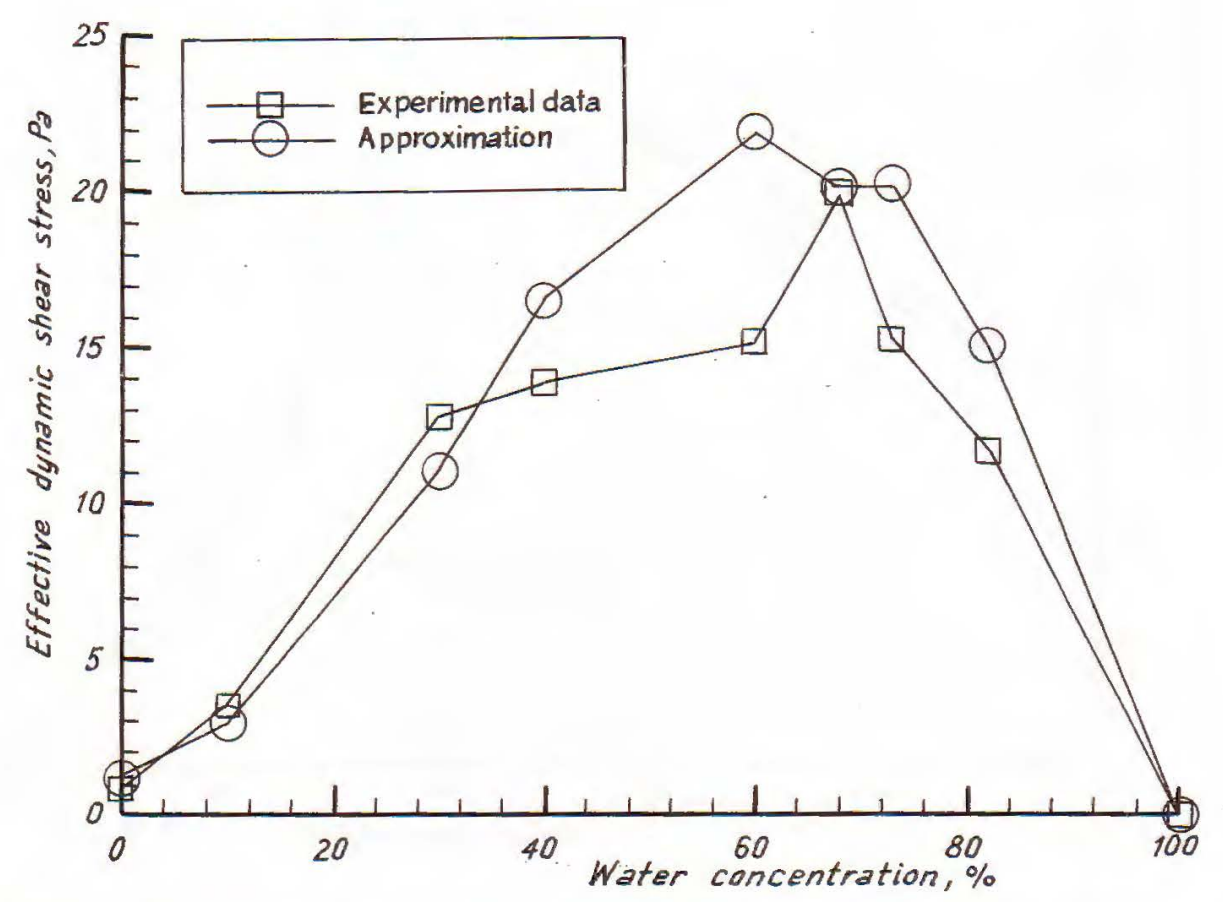

Fig. 11. Comparison of calculation results of (3.19), (3.20) with measurement data for $p=1 \mathrm{~atm}, T=26^{\circ} \mathrm{C}$, and for the case with chemical treatment using reagent ES-3363 of concentration $c=0.1 \%$ 


\section{Conclusion}

In the paper the rheological properties of crude oil of White Tiger oil-field (Vietnam) and its emulsion with sea-water, including measurement and analytical approximation formulae for wide range of pressure, temperature and water concentration, are presented. Beside the effective viscosity of emulsion, the effective dynamic shear stress of emulsion for crude oil - non-Newtonian fluid of Shvedov-Bingham group - with water is measured and approximated. The similar rheological properties of emulsion are also measured and approximated for the case with chemical treatment using reagent ES-3363. The obtained measurement results and the analytical approximation can be used for analysing different situations occured in the practice and also in different numerical code for oil-water mixture flow modelling.

The research is partly supported by National Basic Research Program in Natural Sciences.

\section{REFERENCES}

1. Duong Ngoc Hai et al. Influence of Heat and Mass Transfer on Dynamics of Multiphase Medium. Proc. of IV National Conf. on Mechanics, Hanoi, 1988, pp.44-47.

2. Duong Ngoc Hai et al. Technology of Exploitation and Transport of HighParaffin and High-Viscous Crude Oil of White Tiger Oil-Field. Inst. of Mech., Hanoi, 1987.

3. Beggs H. D. Production Optimization Using Nodal Analysis. Oil-Gas Consultants Int. Inc., USA, Tulsa, Oklahoma, 1991.

4. Beggs H. D. and Robinson J. R. Estimating the Viscosity of Crude Oil System. JPT, Sept., 1975.

5. Gimatudinov Sh. K. (Ed.) Handbook of Oil Exploitation. Publ. Nedra, Moscow, 1974.

6. Gillies R., Shook C. A. Emulsions for Short Distance Transportation of Heavy Crude Oil. Pipeloop Test Results. Proc. Quart. Meeting of Can. Heavy Oil Assoc., Calgary, 1989.

7. Iktisanov V., Sakharov V. A. Determination of Rheological Characteristics of non-Newtonian Systems. Trans. of Colloid J. of USSR, Vol.54, No. 2, 1992, pp.84-89.

8. Brinkman H. The Viscosity of Concentrated Suspensions and Solutions. J. Chemical Physics, Vol.20, No.4, 1952.

9. Jiyong Cai, Tingkuan Chen, Yushan Luo. The Experimental Investigation on the Pressure Drop of the Three-Phase Flow of Gas, Water-Oil Emulsion in 
Horizontal Pipes. Proc. 3-rd Intern. Conf. on Multiphase Flow ICMF'98, Lyon, France, June 8-12, 1998.

10. Harald Kvandal et al. Frictional Pressure Loss for Stable Oil-Water Emulsion in Pipe Flow. J. Two-Phase Flow Modelling and Experimention, 1995, pp.601-608.

11. Pal R. et al. Pipeline Flow of Unstable and Surfactant-Stabilized Emulsions. AICHE J., No. 11, Vol. 39, 1993, pp.1754-1764.

12. Rose S. C. and Marsden Jr. S. S. The Flow of North Slope Crude Oil and Its Emulsions at low Temperatures. Paper SPE 2996, SPE 45th Annual Fall Meeting \& Exhibition, Houston, 1970.

13. Camy et al. The Rheology of Crude Oil Dispersion, Paper SPE 5229, 2nd Int. Symp. on Oilfield Chemistry, Dallas, 1975.

14. Mao M. and Marsden S. S. Stability of Concentrated Crude Oil-in-Water Emulsions as a Function of Shear Rate, Temperature and Oil Concentration. J.Can. Petroleum, Vol. 16, No. 2, 1977, pp.54-59.

15. Pal R., Rhodes E. Transport Characteristics of Emulsion. Paper 85-36-12, 36th Annual Technical Meeting of Petroleum Society of Can. Inst. Min. \& Metallurgy, Edmonton, Alberta, 1985.

16. Vermeulen T., Williams G. M., and Langlous G. E. Interfacial Area in LiquidLiquid and Gas Liquid Agitation. J. Chem. Eng. Progress, Vol.51, No.2, 1955, pp. 85-94.

17. Mewes D., Nadler M. and Tukarz A. The Effect of Emulsification on the Flow Behavior of Two Immisible Liquids in the Horizontal Pipes. Int. Symp. on Liquid-Liquid Two-Phase Flow and Transport Phenomena. Antalya, Turkey, 3-7 Nov., 1977.

18. Ha Van Bich. The Studies of Thixotropic Properties of Waxy Crude Oil from White Tiger and Dragon Oil-Fields. J. Mech., Vol. 18, No.4, 1996, pp. 23-28.

Received June 7, 1999

\section{TÍNH CHẤT LUU BIẾN NHŨ DẦU THÔ VÀ NƯOC}

Bài báo trình bày kết quả đo đạc cũng như các công thức xấp xỉ giải tích tính chất lưu biến của dầu và nhũ bao gồm dầu thô mỏ Bạch Hổ (Việt Nam) và nước biển trong dải thay đởi rộng của áp suất, nhiệt độ và độ ngậm nước. Dầu thô mó Bạch Hổ là dầu thô nhiều paraffin có độ nhớt cao. Khi hạ nhiệt độ xuống thấp hơn $\sim 40^{\circ} \mathrm{C}$ dầu có tính chất của chất lơng phi Niutơn dạng Shvedov-Bingham. Bởi vậy ngoài độ nhớt hiệu dụng, ứng suất trượt động hiệu dụng của nhũ cũng được đo và xấp xỉ bằng các công thức giải tích. Tính chất lưu biến của nhũ còn được đo đạc và xấp xỉ bằng các công thức giải tích khi dầu được xứ lý băng hóa phẩm ES-3363 nồng độ $0.1 \%$. 